\title{
Efficient synthesis of 5-substituted 2-aryl-6-cyanoindolizines via nucleophilic substitution reactions
}

\author{
Eugene V. Babaev ${ }^{*}$, Natalya I. Vasilevich and Anna S. Ivushkina
}

\section{Preliminary Communication}

\section{Address:}

Department of Chemistry, Moscow State University, 119992,

Moscow, Russia

\section{Email:}

Eugene V. Babaev* - babaev@org.chem.msu.su;

Natalya I. Vasilevich - nikto25@hotmail.com; Anna S. Ivushkina -

anna@hotmail.ru

* Corresponding author

Keywords:

5-chloroindolizine; 5-substituted indolizines; 5-indolizinone;

nucleophilic substitution
Open Access

Beilstein Journal of Organic Chemistry 2005, 1, No. 9.

doi:10.1186/1860-5397-1-9

Received: 11 June 2005

Accepted: 07 October 2005

Published: 07 October 2005

(c) 2005 Babaev et al; licensee Beilstein-Institut.

License and terms: see end of document.

\begin{abstract} ised indolizines.

Indolizines are an important class of heterocyclic compounds since many natural alkaloids contain in their structure a saturated (swainsonine) or aromatic (camptothecin) indolizine moiety. While the chemistry of indolizines has been widely investigated[1] the chemistry of 5-substituted indolizines remains very poor because there are only a few reliable ways for their synthesis.
\end{abstract}

2-Aryl-6-cyano-7-methyl-5-indolizinones were successfully converted into 2-aryl-5-chloro-6-cyano-7-methylindolizines. The obtained 5-chloroindolizines readily underwent nucleophilic substitution at position 5 leading in high yields to novel 5-functional-

8-Nitroindolizines may undergo amination at position $5\left(\mathrm{~S}_{\mathrm{N}} \mathrm{H}\right.$ substitution) under the action of secondary amines.[2] 2-Phenylindolizine can be lithiated at position 5, and the resulting indolizyl lithium can react with some electrophiles $\left(\mathrm{CO}_{2}, \mathrm{PhCHO}, \mathrm{PhCN}, \mathrm{Me}_{3} \mathrm{SiCl}, \mathrm{MeI}\right)$ leading to variety of new products in good yields.[3] An interesting method for preparing 5 -substitutied indolizines by recyclization of oxazolo[3,2-a] pyridinium salts was developed in our laboratory.[4,5] Using this strategy a series of 5-substituted indolizines have been prepared in good yields, but (although the method seems to be quite reliable) it is currently restricted only by secondary amines.

In seeking for a synthetic approach to 5-substituted indolizines we have assumed that indolizines bearing an appropriate leaving group (e.g. halogen) at position 5 may undergo nucleophilic substitution. Herein we discuss the synthesis of previously unknown 5-chloroindolizines and their use as precursors 


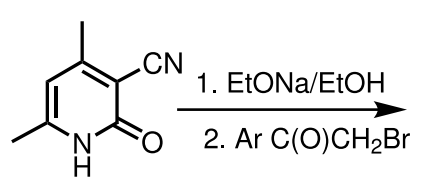<smiles>Cc1cc(C)c(C#N)c(OCC(=O)Br)n1</smiles><smiles>CCO[Mg]O[Mg]</smiles>

$1 a-d$

1 a: $\mathrm{Ar}=p-\mathrm{F}-\mathrm{C}_{6} \mathrm{H}_{4}$

$1 \mathrm{~b}: \mathrm{Ar}=p-\mathrm{Cl}-\mathrm{C}_{6} \mathrm{H}_{4}$

$1 \mathrm{c:}: \mathrm{Ar}=p-\mathrm{Br}-\mathrm{C}_{6} \mathrm{H}_{4}$

1 d: $\mathrm{Ar}=p-\mathrm{Me}-\mathrm{C}_{6} \mathrm{H}_{4}$

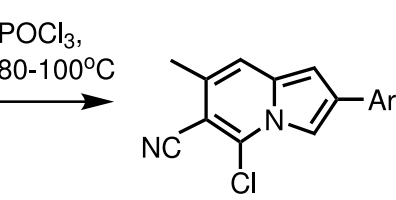

$2 \mathrm{a}-\mathbf{d}$

$2 \mathrm{a}: \mathrm{Ar}=p-\mathrm{F}-\mathrm{C}_{6} \mathrm{H}_{4}$

$2 \mathbf{b}: \mathrm{Ar}=p-\mathrm{Cl}-\mathrm{C}_{6} \mathrm{H}_{4}$

2 c: $\mathrm{Ar}=p-\mathrm{Br}-\mathrm{C}_{6} \mathrm{H}_{4}$

$2 \mathrm{~d}: \mathrm{Ar}=p-\mathrm{Me}-\mathrm{C}_{6} \mathrm{H}_{4}$<smiles>Cc1cc2n(c(=O)c1C#N)CC([Al])=C2</smiles>

A

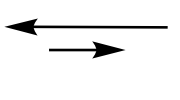

$\mathrm{NC}$<smiles>Cc1cc2cc(Br)cn2c(O)c1C#N</smiles>

B

Scheme 1: Synthesis of 2-aryl-5-chloro-6-cyano-7-methylindolizines 2. Possible tautomeric structures A and B for 2-aryl-6-cyano-7-methyl-5-indolizinones 1.

to novel 5-substituted indolizines via nucleophilic displacement reactions.

The synthesis of 2-aryl-5-chloro-6-cyano-7-methylindolizines 2 is shown in Scheme 1. 2-Aryl-6-cyano-7-methyl-5-indolizinones $1 \mathbf{a}-\mathbf{d}$ were prepared according to protocol of Gevald.[6] Our modification of the original method included separation of $\mathrm{N}$ - and $\mathrm{O}$-isomers of phenacyl pyridines before cyclization (using the difference in their solubility in chloroform). Although ${ }^{1} \mathrm{H}-\mathrm{NMR}$ (see Supporting Information File 2) and Nuclear Overhauser Effect confirmed the structure $\mathbf{A}$ for indolizinones 1, we assumed the existence of tautomerism between forms $\mathbf{A}$ and $\mathbf{B}$ involving hydrogen interchange between oxygen and C-3 carbon (Scheme 1). Although the amount of tautomer $\mathbf{B}$ is negligibly small, one would expect that treatment of $\mathbf{1} \mathbf{a}-\mathbf{d}$ with phosphorous oxychloride may lead to substitution of oxo/oxy-group to chlorine giving the products 2 a - d. (It is well known that analogous 2-hydroxypyridines which exist in the pyridone tautomeric form can be easily converted to 2-chloroderivatives by reaction with $\mathrm{POCl}_{3}$.).[7] Indeed, heating of indolizinones $\mathbf{1} \mathbf{a}-\mathbf{d}$ in $\mathrm{POCl}_{3}$ at $80-100^{\circ} \mathrm{C}$ during 10 hours without any solvent followed by pouring into a mixture of ice/sodium acetate and filtration of the green precipitate afforded crude 5-chloroindol- izines. After column chromatography (eluent - carbon tetrachloride) yellow solids were obtained. Performing this reaction in the presence of two-fold molar excess of trimethylbenzylammonium chloride or TEBAC increased the yields of $\mathbf{2} \mathbf{a}-\mathbf{d}$ up to $30-75 \%$. In the ${ }^{1} \mathrm{H}$ NMR spectra of these products ${ }^{\dagger}$ the initial signal of $3-\mathrm{CH}_{2}$ group at $\sim 5 \mathrm{ppm}$ (intensity $2 \mathrm{H}$ ) disappeared, and a new aromatic signal 3-CH (with intensity $1 \mathrm{H}$ ) appeared at $7.99-8.11 \mathrm{ppm}$.

The halogen atom in 5-chloro-6-cyanoindolizines $\mathbf{2}$ should be activated to nucleophilic substitution reactions by the suitable ortho-arrangement of the nitrogen atom of the pyridine ring and electron-withdrawing cyano-group. The pattern strongly resembled 2-chloro-3-cyanopyridine, that is why we anticipated successful substitution in reactions of 2 with oxygen, nitrogen, and sulfur nucleophiles. Indeed, 5-chloroindolizines readily underwent nucleophilic substitution to produce previously unknown compounds $\mathbf{3}-\mathbf{6}$ in good to excellent yields (Scheme 2). These products are detailed in Table 2. Thus, 5-methoxyindolizines $3 \mathbf{a}-\mathbf{c}$ were formed after refluxing $\mathbf{2} \mathbf{b}-$ $\mathbf{d}$ in solution of sodium methoxide in methanol overnight in good yields (Scheme 2). Treatment of $\mathbf{2 a}$, $\mathbf{d}$ with excess of amines without any solvent gave 5-amino derivatives $4 \mathbf{a}-\mathbf{h}$. In the case of secondary amines $(4 \mathbf{a}-\mathbf{c}, \mathbf{e}-\mathbf{g})$ the reaction 
proceeded at room temperature, but reaction with less nucleophilic benzylamine $(\mathbf{4} \mathbf{d}, \mathbf{h})$ required heating for $30 \mathrm{~min}$. Nucleophilic substitution also occured with sulfur nucleophiles. Thus, $2 \mathbf{d}$ reacted with mercaptoethanol under basic conditions leading to 5a. Conversion 2a into $\mathbf{5 b}$ was conveniently achieved with ethyl mercaptoacetate in ethanolic sodium hydroxide. Interestingly, 2a reacted also with thiourea in refluxing butanol giving indolizinethione $\mathbf{6}$. The product $\mathbf{6}$ seems to be the result of decomposition of unstable isothiouronium salt, and the process resembles the known conversion of 2-chloro-3-cyanopyridines to 3-cyanopyridinethiones under the same conditions via a similar intermediate. $[8]^{1} \mathrm{H}$ NMR spectrum of $\mathbf{6}$, which was very similar to the spectra of $\mathbf{1}$, indicated disappearance of aromatic proton signal $\mathrm{H}_{3}$ and appearance of a signal at $5.35 \mathrm{ppm}$ with intensity $2 \mathrm{H} .^{\dagger}$

In conclusion, we are the first to obtain 2-aryl-5-chloro-6cyano-7-methylindolizines from 2-aryl-6-cyano-7-methyl-5indolizinones and to prove the possibility to employ them in

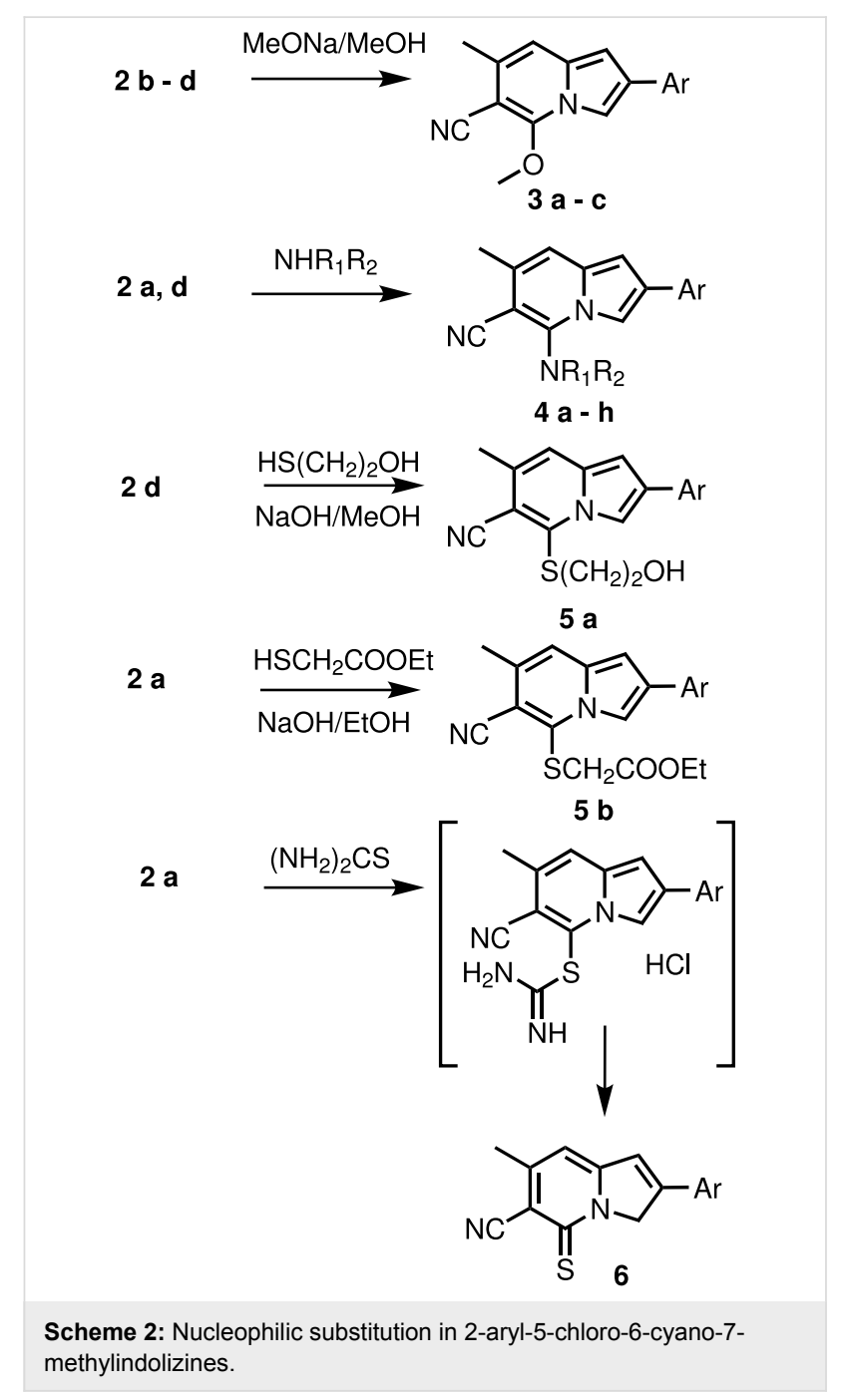

Table 1: Properties of 5-substituted 2-aryl-6-cyano-7-methylindolizines<smiles>[X]c1c(C#N)c(C)cc2cc([Al])cn12</smiles>

No. $5-X^{*}$ $\mathrm{R}$ in 2-Ar Yield \% m.p., ${ }^{\circ} \mathrm{C}$

2 a $\mathrm{Cl}$

2 b $\mathrm{Cl}$

2 c $\mathrm{Cl}$

2 d Cl

3 a OMe

3 b $\mathrm{OMe}$

3 c OMe

4 a pyrrolidyl

4 b piperidyl

p-F $\quad 30 \quad 173-175$

4 c hexamethy-lenimino

$\mathrm{p}-\mathrm{Cl} \quad 65$

198-200

p-Br 54

229-230

p-Me 74

157-158

p-Cl 50

169-172

$\mathrm{p}-\mathrm{Br} \quad 71$

197-200

p-Me $\quad 73$

170-173

p-F $\quad 99$

189-190

p-F $\quad 91$

205-209

4 d benzylamino

186-188

4 e pyrrolidyl

$p-F$

$p-F$

$\mathrm{p}-\mathrm{Me}$

190-194

4 f piperidyl

p-Me

228-230

$4 \mathrm{~g}$ hexamethy-lenimino

$12-215$

$4 \mathrm{~h}$ benzylamino

$\mathrm{p}-\mathrm{Me}$

213-216

5 a $\mathrm{S}\left(\mathrm{CH}_{2}\right)_{2} \mathrm{OH}$

$\mathrm{p}-\mathrm{Me}$

185-187

5 b $\mathrm{SCH}_{2} \mathrm{CO}_{2} \mathrm{Et}$

$\mathrm{p}-\mathrm{Me}$

132-135

$p-F$

142-145

nucleophilic substitution reactions. Moreover, these reactions are the first examples of preparative nucleophilic substitution in indolizines, and our findings open a new way to functionalize the $\mathrm{C}-5$ position (in most cases considered as inactive). The studies of further cyclizations of 5-substituted indolizines involving neighbouring cyano-group and ring position $\mathrm{C}_{3}$ is underway.

\section{Note}

*Characteristics of parent indolizinones $\mathbf{1} \mathbf{a}-\mathbf{d}$ were identical to those described in literature.[9]

$\dagger$ Supporting information

\section{Supporting Information}

\section{Supporting Information File 1}

Supporting tables

[http://www.beilstein-journals.org/bjoc/content/

supplementary/1860-5397-1-9-S1.doc]

\section{Supporting Information File 2}

Supporting information

[http://www.beilstein-journals.org/bjoc/content/ supplementary/1860-5397-1-9-S2.pdf] 


\section{Acknowledgments}

This work was supported by Russian Foundation of Basic

Research (grant 04-03-32823).

\section{References}

1. Flitch, W. Pyrroles with fused six-membered heterocyclic rings: a-fused. In Comprehensive Heterocyclic Chemistry; Katritzky, A. R.; Rees, C. W., Eds.; Pergamon Press: London, 1984; Vol. 4, pp 443-478.

2. Kost, A. N.; Sagitullin, R. S.; Gromov, S. P. Heterocycles 1977, 7, 997-1001.

3. Renard, M.; Gubin, J. Tetrahedron Lett. 1992, 33, 4433-4434. doi:10.1016/S0040-4039(00)60102-8

4. Babaev, E. V.; Efimov, A. V.; Maiboroda, D. A.; Jug, K. Eur. J. Org. Chem. 1998, 1, 193-196. doi:10.1002/(SICl)1099-0690(199801)1998:1<193::AID-EJOC193>3.0. CO;2-6

5. Babaev, E. V. J. Heterocycl. Chem. 2000, 37, 519-526.

6. Gevald, K.; Jansch, H. J. J. Prakt. Chem. 1976, 318, 313-320. doi:10.1002/prac.19763180216

7. Kwok, R. J. Heterocycl. Chem. 1978, 15, 877-880.

8. Kitaygorodova, E. A.; Konyushkin, L. D.; Mikhaychenko, S. N. Khim. Geterotsikl. Soedin. 1999, 3, 337-341. (Rus).

9. Lin, C. F.; Lin, Y. F.; Lo, Y. C.; Chen, K. T.; Su, T. L. Heterocycles 2000, 1, 15-26.

\section{License and Terms}

This is an Open Access article under the terms of the Creative Commons Attribution License (http://creativecommons.org/licenses/by/2.0), which permits unrestricted use, distribution, and reproduction in any medium, provided the original work is properly cited.

The license is subject to the Beilstein Journal of Organic Chemistry terms and conditions:

(http://www.beilstein-journals.org/bjoc)

The definitive version of this article is the electronic one which can be found at: doi:10.1186/1860-5397-1-9 